\title{
Our experience with aortic valve repair with a remodeling technique, extraaortic ring implantation and root replacement
}

\author{
(D) Josip Varvodić1*, \\ (DSavica Gjorgjievska', \\ (iD)Davor Barić1, \\ (D)Daniel Unić', \\ (D)Mislav Planinc', \\ (D)Marko Kušurin', \\ (DD) Dubravka Šunjar', \\ DSandra Jakšić \\ Jurinjak', \\ (DIvana Jurin', \\ (D) Nikola Bulj², \\ (DIgor Rudež 1
}

'University Hospital Dubrava, Zagreb, Croatia

2University Hospital Centre "Sestre milosrdnice", Zagreb, Croatia

RECEIVED:

August 26, 2019

ACCEPTED:

September 16, 2019

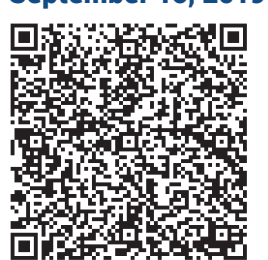

KEYWORDS: aortic valve reconstruction, aortic root replacement, annuloplasty. CITATION: Cardiol Croat. 2019;14(9-10):227. | https://doi.org/10.15836/ccar2019.227

*ADDRESS FOR CORRESPONDENCE: Josip Varvodić, Mesnička 7, HR-10000 Zagreb, Croatia. / Phone: +385-993553-909 / E-mail: josip.varvodic@gmail.com

ORCID: Josip Varvodić, https://orcid.org/0000-0001-6602-699X • Savica Gjorgjievska, https://orcid.org/0000-0002-4304-1852 Davor Barić, https://orcid.org/0000-0001-5955-0275 • Daniel Unić, https://orcid.org/0000-0003-2740-4067 Mislav Planinc, https://orcid.org/0000-0002-9833-832X • Marko Kušurin, https://orcid.org/0000-0001-5690-9924 Dubravka Šušnjar, https://orcid.org/0000-0002-9644-9739 • Sandra Jakšić Jurinjak, https://orcid.org/0000-0002-7349-6137 Ivana Jurin, https://orcid.org/0000-0002-2637-9691 • Nikola Bulj, https://orcid.org/0000-0002-7859-3374 Igor Rudež, https://orcid.org/0000-0002-7735-6721

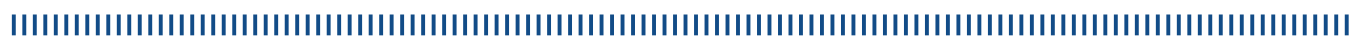

Objective: Aortic valve replacement (AVR) is still the most commonly used therapeutic option for patients suffering from AR. Aortic valve repair (AVRep) is an attractive alternative method, since it avoids the risks of prosthesis-related complications.$^{1-3}$ We would like to present our experience with the Yacoub root remodeling, valve sparing technique with the extraaortic expansible ring.

Patients and Methods: Between November 2014 and July 2019, a total of 79 patients (52.6 \pm 13.3 years; $15.2 \%$ female, EuroScore II of 3.15\% 2 ) underwent AVRep, 12 due to isolated cusp malcoaptation and 67 associated with aortic root dilatation. Reconstruction was done with the Coroneo Extraaortic Ring (27 (25-31)), and the Gelweave graft (28 (26-32)). 44 patients had a tricuspid valve, 33 patients had a bicuspid valve, and 2 patients had an unicuspid valve. Concomitant procedures included Mvrep and TVrep in 4 patients, CABG in two patents. Aortic arch was replaced in two patients, two patients underwent hemiarch replacement, and two patients had aortic arch replacement with stented conduit and placement of stent in descending thoracic aorta (EVITA stent graft Jotec $\mathrm{GmbH}$ ). Echocardiography was used to determine AR severity grade preoperatively, during immediate post-operative period (within 7 days from operation) and at early follow-up.

Results: In postoperative follow-up no patients died. Freedom from reoperation was 88\% (10/79) and there were 2 patients reoperated due to early postoperative regurgitation, one patient was reoperated due to AI after two years, and one was operated due to pseudoaneurysm formation after 2.5 years. A significant decrease in LV end-diastolic diameter was observed (LVEDD) (60mm preoperatively, $53 \mathrm{~mm}$ postoperatively) with further decrease at early follow-up. At follow up none of the patients had major $\operatorname{AR}(\mathrm{AR} 0=61, \mathrm{AR} 1+=14, \mathrm{AR} 2+=4)$.

Conclusions: We have proved that AVRep is a good alternative for patients with aortic insufficiency and leads to LV reverse remodeling with comparable results in terms of LVEDD and LVEF immediately post-operatively and at early follow up. It is feasible to use this technique in tricuspid, bicuspid, as well as unicuspid valves with excellent results.

LITERATURE IIIIIIIIIIIIIIIIIIIIIIIIIIIIIIIIIIIIIIIIIIIIIIIIIIIIIIIIIIIIIIIIIIIIIIIIIIIIIIIIIIIIIIIIIIIIIIIIII

1. de Heer F, Lansac E, El-Hamamsy I, Pibarot P, De Kerchove L, El Khoury G, et al. The AVIATOR registry: the importance of evaluating long-term patient outcomes. Ann Cardiothorac Surg. 2019 May:8(3):393-395. https://doi.org/10.21037/acs.2019.04.08

2. Lansac E, Di Centa I, Vojacek J, Nijs J, Hlubocky J, Mecozzi G, et al. Valve sparing root replacement: the remodeling technique with external ring annuloplasty. Ann Cardiothorac Surg. 2013 Jan;2(1):117-23. https://doi.org/10.3978/j.issn.2225-319X.2013.01.15

3. Lansac E, Di Centa I, Raoux F, Bulman-Fleming N, Ranga A, Abed A, et al. An expansible aortic ring for a physiological approach to conservative aortic valve surgery. J Thorac Cardiovasc Surg. 2009 Sep;138(3):718-24. https://doi.org/10.1016/j.jtcvs.2009.05.024 